\title{
Effects of Antimalarial Tafenoquine on Blood Platelet Activity and Survival
}

\author{
Hang Cao ${ }^{a}$ Rosi Bissinger ${ }^{a}$ Anja T. Umbacha Abdulla Al Mamun Bhuyan ${ }^{a}$ \\ Meinrad Gawaz Florian Langa,b
}

aDepartment of Internal Medicine III, Eberhard-Karls-University, Tuebingen, ${ }^{b}$ Department of Molecular Medicine II, Heinrich Heine University Duesseldorf, Duesseldorf Germany

\section{Key Words}

Cytosolic $\mathrm{Ca}^{2+}$ concentration - Phosphatidylserine translocation • P-selectin • Integrin • Caspase - Cell volume

\begin{abstract}
Background/Aims: The 8-aminoquinoline tafenoquine has been shown to be effective against Plasmodia, Leishmania and Trypanosoma. The substance is at least in part effective by triggering apoptosis of the parasites. Moreover, tafenoquine has been shown to trigger eryptosis, the suicidal erythrocyte death characterized by cell shrinkage and cell membrane scrambling with phosphatidylserine translocation to the erythrocyte surface. The effect of tafenoquine on eryptosis is in part due to stimulation of $\mathrm{Ca}^{2+}$ entry and oxidative stress. $\mathrm{Ca}^{2+}$ entry is a critical event in the activation of blood platelets by thrombin and collagen related peptide (CRP). The present study explored, whether tafenoquine influences $\mathrm{Ca}^{2+}$ entry, activation and apoptosis of blood platelets. Methods: Platelets isolated from wild-type mice were exposed for 30 minutes to tafenoquine $(2.5 \mu \mathrm{g} / \mathrm{ml})$ without or with an additional treatment with thrombin $(0.01 \mathrm{U} / \mathrm{ml})$ or CRP $(2 \mu \mathrm{g} / \mathrm{ml}$ or $5 \mu \mathrm{g} / \mathrm{ml}$ ). Flow cytometry was employed to estimate cytosolic $\mathrm{Ca}^{2+}$-activity $\left(\left[\mathrm{Ca}^{2+}\right]_{i}\right)$ from Fluo3 fluorescence, platelet degranulation from P-selectin abundance, integrin activation from $\alpha_{\text {IIb }} \beta_{3}$ integrin abundance, phosphatidylserine abundance from annexin-V-binding, relative platelet volume from forward scatter, reactive oxygen species (ROS) from DCF fluorescence, caspase 3 activity with an active caspase-3 Staining kit, and aggregation utilizing staining with CD9-APC and CD9-PE. Results: Both, thrombin $(0.01 \mathrm{U} / \mathrm{ml})$ and CRP $(2 \mu \mathrm{g} / \mathrm{ml}$ or $5 \mu \mathrm{g} / \mathrm{ml})$, significantly increased $\left[\mathrm{Ca}^{2+}\right]_{\mathrm{i}}$ P-selectin abundance, active $\alpha_{\mathrm{Ib}} \beta_{3}$ integrin, and annexin-V-binding, and both significantly decreased platelet volume, activated caspase 3 and stimulated aggregation. Administration of tafenoquine $(2.5 \mu \mathrm{g} / \mathrm{ml}, 30 \mathrm{~min})$ significantly decreased $\left[\mathrm{Ca}^{2+}\right]_{\mathrm{i}}$ both, in the absence and presence of thrombin and CRP. Tafenoquine significantly blunted the effect of thrombin and CRP on $\left[\mathrm{Ca}^{2+}\right]_{i^{\prime}}$ P-selectin abundance, and active $\alpha_{\mathrm{mb}} \beta_{3}$ integrin, but significantly increased ROS and annexin-V-binding, significantly augmented the effect of thrombin on caspase 3 activity and platelet volume and significantly enhanced platelet aggregation. Conclusions: Tafenoquine counteracts thrombin and CRP induced increase of cytosolic Ca ${ }^{2+}$ activity and platelet activation, but enhances platelet apoptosis and platelet aggregation.
\end{abstract}




\section{Introduction}

The antimalarial drug tafenoquine [1-8] is effective against all stages of the Plasmodium vivax life cycle including the liver stage and is thus mainly considered for prevention of relapsing Plasmodium vivax infection [1, 8-27]. Tafenoquine could be further used for the treatment of trypanosoma brucei [28, 29] and leishmania [29-33] infection. Most recently, tafenoquine has been shown to trigger eryptosis, the suicidal death of erythrocytes characterized by cell shrinkage and phospholipid scrambling of the erythrocyte cell membrane [34]. The effect was due to stimulation of $\mathrm{Ca}^{2+}$ entry and oxidative stress [34].

$\mathrm{Ca}^{2+}$ entry is a critical event in the activation of blood platelets by thrombin and collagen related peptide (CRP), which contribute to primary hemostasis following vascular injury and by the same token are involved in the pathophysiology of acute thrombotic occlusion [35]. $\mathrm{Ca}^{2+}$ entry into platelets is triggered by $\mathrm{Ca}^{2+}$ release from intracellular stores [36] and subsequent activation of $\mathrm{Ca}^{2+}$ release-activated channel Orai1 in the plasma membrane [37-40]. The increase of cytosolic $\mathrm{Ca}^{2+}$ activity triggers activation of $\alpha_{\mathrm{IIb}} \beta_{3}$ integrin and degranulation, the latter being apparent from increase of P-selectin abundance $[41,42] . \mathrm{Ca}^{2+}$ entry may further be followed by stimulation of platelet apoptosis, which is apparent from caspase activation, cell membrane scrambling and platelet shrinkage $[43,44]$.

The present study explored, whether tafenoquine influences $\mathrm{Ca}^{2+}$ entry, activation and apoptosis of blood platelets. To this end, murine platelets were exposed to tafenoquine prior to and following activation with thrombin or CRP and cytosolic $\mathrm{Ca}^{2+}$ activity $\left(\left[\mathrm{Ca}^{2+}\right]_{\mathrm{i}}\right)$, P-selectin abundance, active $\alpha_{\mathrm{IIb}} \beta_{3}$ integrin, reactive oxygen species, cell membrane scrambling, platelet volume, caspase activity, and aggregation determined by flow cytometry.

\section{Materials and Methods}

\section{Mice}

All animal experiments were conducted according to the German law for the welfare of animals and were approved by the authorities of the state of Baden-Württemberg. Experiments were performed with blood platelets isolated from wild type mice. The mice had free access to water and control chow (Ssniff, Soest, Germany).

\section{Preparation of mouse platelets}

Platelets were obtained from 10 - to 12 -week-old mice of either sex. The mice were anesthetized and $800 \mu \mathrm{l}$ blood was drawn from the retro-orbital plexus into tubes with $200 \mu \mathrm{l}$ acid-citrate-dextrose buffer before the mice were sacrificed [45]. Platelet rich plasma (PRP) was obtained by centrifugation at $260 \mathrm{~g}$ for 5 minutes. Afterwards, PRP was centrifuged at $640 \mathrm{~g}$ for 5 minutes to pellet the platelets. Where necessary, apyrase (0.02 U/ml; Sigma-Aldrich) and prostaglandin $\mathrm{E}_{2}(0.5 \mu \mathrm{M}$; Calbiochem) were added to the PRP to prevent activation of platelets during isolation. After two washing steps, the pellet of washed platelets was resuspended in modified Tyrode-HEPES buffer ( $\mathrm{pH} 7.4$, supplemented with $1 \mathrm{mM} \mathrm{CaCl}_{2}$ ). Where indicated, thrombin (Roche, Basel, Switzerland) was added at the indicated concentrations [46].

\section{Cytosolic calcium}

For the measurement of the cytosolic $\mathrm{Ca}^{2+}$ concentration, the platelet preparation was washed once in Tyrode buffer ( $\mathrm{pH}$ 7.4), stained with $3 \mu \mathrm{M}$ Fluo-3AM (Biotinium, USA) in the same buffer and incubated at $37^{\circ} \mathrm{C}$ for 30 minutes. Following the indicated experimental treatment, fluorescence was measured at an excitation wavelength of $488 \mathrm{~nm}$ and an emission wavelength of $530 \mathrm{~nm}$ utilizing a BD FACSCalibur (BD Biosciences, Heidelberg, Germany) [46].

\section{$P$-selectin and activated integrin abundance}

Fluorophore-labeled antibodies were utilized for the detection of P-selectin surface abundance (Wug. E9-FITC) and the active form of $\alpha_{\mathrm{IIb}} \beta_{3}$ integrin (JON/A-PE). Washed mouse platelets $\left(1 \times 10^{6}\right)$ were suspended in modified Tyrode buffer ( $\mathrm{pH}$ 7.4) containing $1 \mathrm{mM} \mathrm{CaCl}_{2}$ and antibodies (1:10 dilution) and subsequently 


\section{Cellular Physiology Cell Physiol Biochem 2017;41:369-380

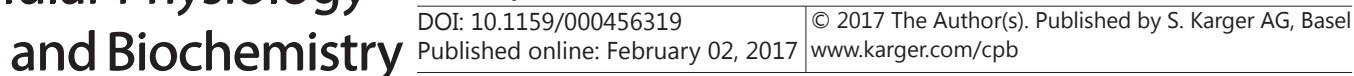 \\ Cao et al.: Tafenoquine Sensitive Platelet Function}

exposed to the respective treatments and for the indicated time periods at room temperature (RT). The reaction was stopped by addition of PBS and the samples were immediately analyzed on a BD FACSCalibur[47].

\section{Phosphatidylserine exposure and forward scatter}

Phosphatidylserine exposure was determined in platelets with and without 10 minutes thrombin or CRP treatment. To this end, the platelet preparation was centrifuged at $660 \mathrm{~g}$ for 5 minutes followed by washing once with Tyrode buffer ( $\mathrm{pH} 7.4$ ) with $1 \mathrm{mM} \mathrm{CaCl}$, staining with 1:20 dilution of Annexin-V FITC (Mabtag, Germany) in Tyrode buffer ( $\mathrm{pH} 7.4$ ) with $2 \mathrm{mM} \mathrm{CaCl}_{2}$ and incubation at $37^{\circ} \mathrm{C}$ for 30 minutes. Annexin- $V$ binding reflecting surface exposure of phosphatidylserine was evaluated by flow cytometry utilizing a BD FACSCalibur. In parallel, the forward scatter (FSC) of the platelets was determined by flow cytometry as a measure of platelet size.

\section{Quantification of reactive oxygen species (ROS)}

Oxidative stress was determined utilizing 2',7'-dichlorodihydrofluorescein (DCF) diacetate. Washed platelets were incubated for 10 minutes $\left(37^{\circ} \mathrm{C}\right)$ with $0.01 \mathrm{U} / \mathrm{ml}$ thrombin and $2 \mu \mathrm{g} / \mathrm{ml} \mathrm{CRP}$, and washed two times with $350 \mu \mathrm{l}$ Tyrode buffer after stimulation by agonists. Subsequently, the platelets were stained with DCF (10 $\mu \mathrm{M}$; Sigma, Schnelldorf, Germany) in Tyrode buffer at $37^{\circ} \mathrm{C}$ for $30 \mathrm{~min}$ and washed once in 150 $\mu \mathrm{l}$ Tyrode buffer. The DCF-loaded platelets were resuspended in $200 \mu \mathrm{l}$ Tyrode buffer and ROS-dependent fluorescence intensity was measured at an excitation wavelength of $488 \mathrm{~nm}$ and an emission wavelength of $530 \mathrm{~nm}$ on a BD FACSCalibur.

Caspase-3 activity

Caspase 3 activity was determined utilizing a CaspGlow Fluorescein Active Caspase-3 Staining kit from BioVision (CA, USA) according to the manufacturer's instruction. Fluorescence intensity was measured at an excitation wavelength of $488 \mathrm{~nm}$ and an emission wavelength of $530 \mathrm{~nm}$ in a BD FACSCalibur (BD Biosciences, USA).

\section{Platelet aggregation}

Aggregation was determined utilizing flow cytometry as previously described $[39,48]$. To this end, platelets were labeled with CD9-APC and CD9-PE monoclonal antibodies (1:100 dilution, Abcam) for 15 minutes at room temperature. Following incubation, differently labeled samples were washed twice, mixed $1: 1$ and then pre-incubated at $37^{\circ} \mathrm{C}$ while shaking at $600 \mathrm{rpm}$ for $10 \mathrm{~min}$. Pre-incubated platelets were activated with thrombin or collagen related peptide at $37^{\circ} \mathrm{C}$ while shaking at $1000 \mathrm{rpm}$. At the indicated time points, samples were fixed by addition of $0.5 \%$ paraformaldehyde (Carl Roth, Germany) in phosphatebuffered saline. The fixed samples were measured utilizing a BD FACSCalibur (BD Biosciences, Heidelberg, Germany). For quantification, a quadrant was set in the dot plot of respective channels on non-stimulated platelets. The appearance of double-colored events in the upper right quadrant (Q2) was taken as evidence for aggregation and quantified as percentage of total amount of labeled events (Q1+Q2+Q4) at every time point analyzed.

\section{Statistical analysis}

Data are provided as means \pm SEM; $n$ represents the number of independent experiments. All data were tested for significance using ANOVA with Tukey's test as post-test or unpaired student's t-test as appropriate. Differences with $p<0.05$ were considered statistically significant.

\section{Results}

The present study explored, whether tafenoquine triggers activation and apoptosis of blood platelets. To this end, murine platelets were isolated from wild type mice and exposed to thrombin $(0.01 \mathrm{U} / \mathrm{ml})$ or collagen related peptide $(2 \mu \mathrm{g} / \mathrm{ml}$ or $5 \mu \mathrm{g} / \mathrm{ml})$ in the absence and presence of tafenoquine $(2.5 \mu \mathrm{g} / \mathrm{ml})$.

In a first series of experiments, cytosolic $\mathrm{Ca}^{2+}$ concentration $\left(\left[\mathrm{Ca}^{2+}\right]_{\mathrm{i}}\right)$ was determined utilizing Fluo-3 fluorescence. As illustrated in Fig. 1, both, thrombin and CRP triggered a sharp 
Fig. 1. Tafenoquine sensitive cytosolic $\mathrm{Ca}^{2+}$ concentration. A-C. Original histogram overlays of Fluo-3 fluorescence reflecting cytosolic $\mathrm{Ca}^{2+}$ activity in murine platelets without (A) and with a treatment with (B) thrombin $(100 \mathrm{~s}, 0.01$ $\mathrm{U} / \mathrm{ml})$ or (C) CRP (150 s, 2 $\mu \mathrm{g} / \mathrm{ml}$ ) without (grey areas) and with (black lines) presence of tafenoquine $(2.5 \mu \mathrm{g} /$ $\mathrm{ml}, 30 \mathrm{~min}$ ). D. Arithmetic means \pm SEM $(n=8)$ of Fluo3 fluorescence reflecting cy-

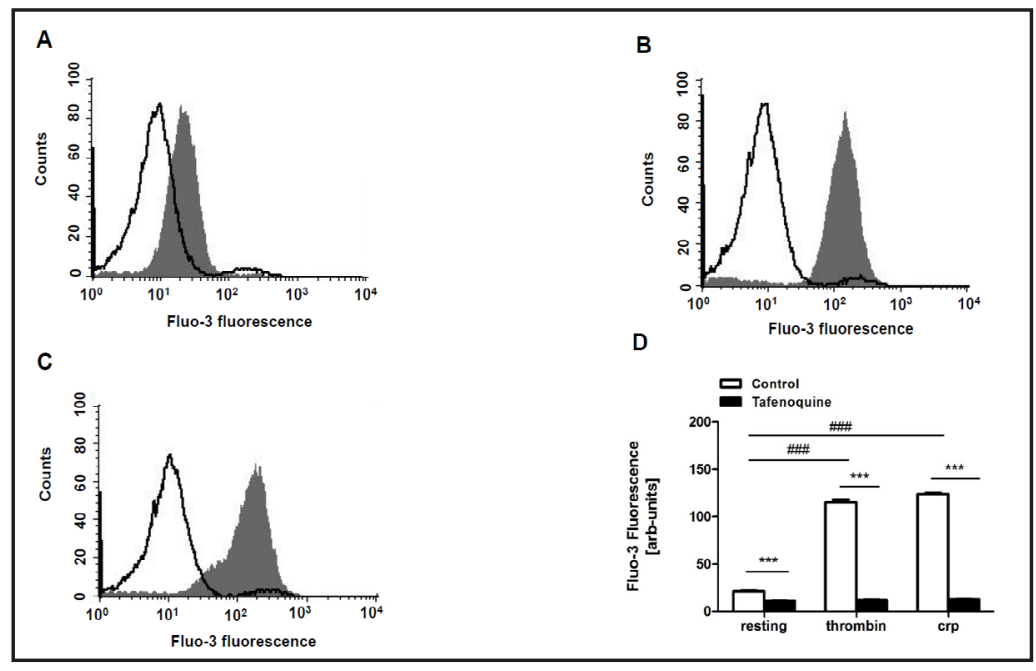
tosolic $\mathrm{Ca}^{2+}$ activity in murine platelets in the absence (white bars) and presence (black bars) of $2.5 \mu \mathrm{g} / \mathrm{ml}$ tafenoquine without (resting) and with addition of thrombin $(0.01 \mathrm{U} / \mathrm{ml})$ or CRP $(2 \mu \mathrm{g} / \mathrm{ml})$. \#\#\# ( $p<0.001)$ indicates statistically significant difference from absence of thrombin and CRP, ${ }^{* * *}(\mathrm{p}<0.001)$ indicates statistically significant difference from absence of tafenoquine.

Fig. 2. Tafenoquine sensitive platelet degranulation. A-C. Original histogram overlays of P-selectin related fluorescence in murine platelets without (A) and with a $15 \mathrm{~min}$ treatment with (B) thrombin $(0.01 \mathrm{U} / \mathrm{ml})$ or (C) CRP $(2 \mu \mathrm{g} /$ $\mathrm{ml}$ ) without (grey areas) and with (black lines) presence of tafenoquine $(2.5 \mu \mathrm{g} / \mathrm{ml}, 30$ min). D. Arithmetic means \pm SEM $(n=6)$ of the P-selectin related fluorescence (arbitrary units) in murine platelets in the absence (white bars) and presence (black

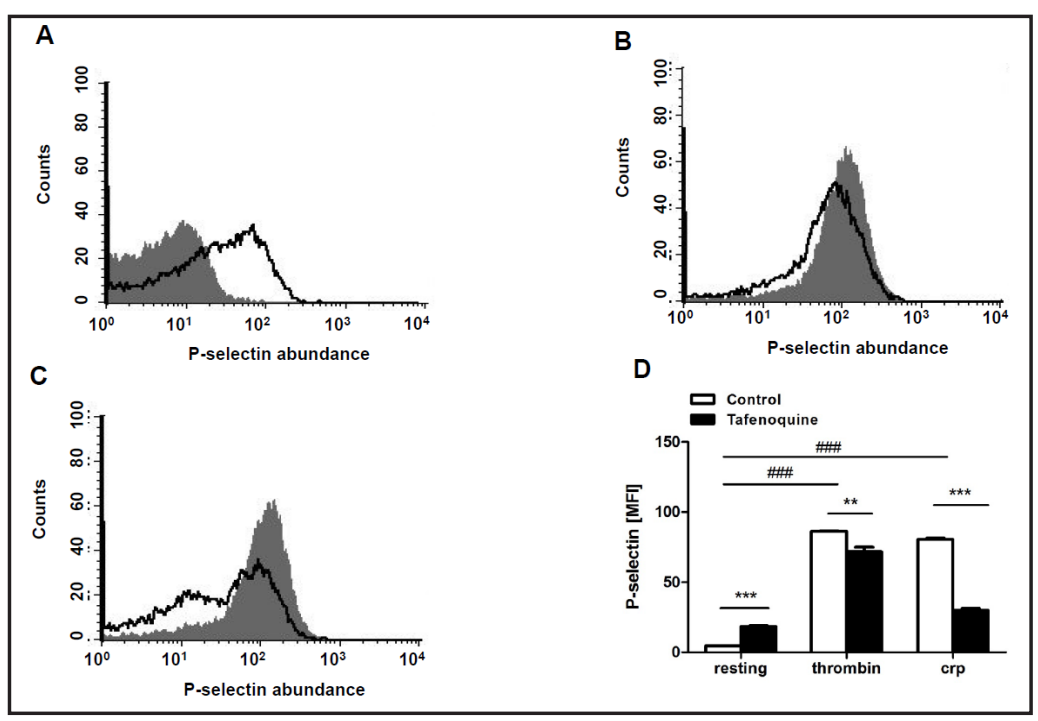
bars) of $2.5 \mu \mathrm{g} / \mathrm{ml}$ tafenoquine without (resting) and with a 15 min thrombin $(0.01 \mathrm{U} / \mathrm{ml})$ or CRP $(2 \mu \mathrm{g} / \mathrm{ml})$ treatment. \#\#\# $(p<0.001)$ indicates statistically significant difference from absence of thrombin and CRP, ${ }^{* *}$ $(p<0.01)^{* * *}(p<0.001)$ indicates statistically significant difference from absence of tafenoquine.

increase of $\left[\mathrm{Ca}^{2+}\right]_{i^{*}}$ Tafenoquine significantly decreased platelet $\left[\mathrm{Ca}^{2+}\right]_{\mathrm{i}}$ both, in the absence and presence of thrombin or CRP. Along those lines, tafenoquine significantly blunted the effect of thrombin and CRP on $\left[\mathrm{Ca}^{2+}\right]_{\mathrm{i}}$ (Fig. 1).

Platelet degranulation was estimated from the increase of P-selectin abundance at the platelet surface, which was determined utilizing specific antibodies and flow cytometry. As illustrated in Fig. 2, tafenoquine slightly but significantly increased the P-selectin abundance in the absence of thrombin or CRP. Treatment with either, thrombin or CRP was followed by a sharp increase of P-selectin abundance, an effect significantly blunted in the presence of tafenoquine (Fig. 2).

The abundance of active integrin $\alpha_{\mathrm{II}} \beta_{3}$ was determined utilizing again specific antibodies and flow cytometry. As illustrated in Fig. 3 , in the absence of thrombin or CRP, tafenoquine slightly but significantly increased the abundance of active integrin $\alpha_{\mathrm{IIb}} \beta_{3}$. Treatment with either, 
Fig. 3. Tafenoquine sensitive integrin $\alpha_{\mathrm{IIb}} \beta_{3}$ activation. A-C. Original histogram overlays of activated $\alpha_{\mathrm{IIb}} \beta_{3}$ integrin related fluorescence in murine platelets without (A) and with a $15 \mathrm{~min}$ treatment with (B) thrombin $(0.01 \mathrm{U} / \mathrm{ml})$ or (C) CRP $(2 \mu \mathrm{g} / \mathrm{ml})$ without (grey areas) and with (black lines) presence of tafenoquine $(2.5 \mu \mathrm{g} / \mathrm{ml}, 30$ min). D. Arithmetic means $\pm \operatorname{SEM}(\mathrm{n}=6)$

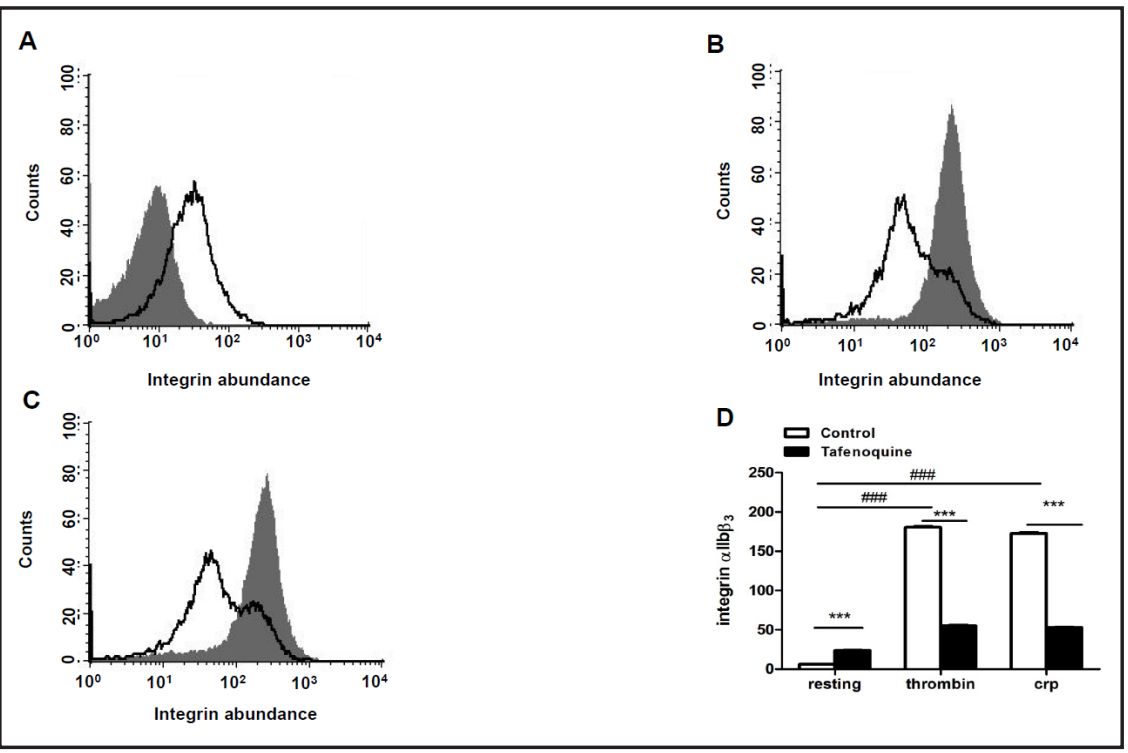
of activated $\alpha_{\mathrm{II}} \beta_{3}$ integrin related fluorescence (arbitrary units) in murine platelets in the absence (white bars) and presence (black bars) of $2.5 \mu \mathrm{g} / \mathrm{ml}$ tafenoquine without (resting) and with a $15 \mathrm{~min}$ thrombin $(0.01 \mathrm{U} / \mathrm{ml})$ or CRP $(2 \mu \mathrm{g} / \mathrm{ml})$ treatment. \#\#\# ( $p<0.001)$ indicates statistically significant difference from absence of thrombin and CRP, ${ }^{* * *}(\mathrm{p}<0.001)$ indicates statistically significant difference from absence of tafenoquine.

Fig. 4. Tafenoquine sensitive cell membrane scrambling. A-C. Original histogram overlays of annexin-V-binding reflecting phosphatidylserine abundance at the surface of murine platelets without (A) and with a 10 min treatment with (B) thrombin $(0.01 \mathrm{U} / \mathrm{ml})$ or $(\mathrm{C})$ CRP $(5 \mu \mathrm{g} / \mathrm{ml})$ without (grey areas) and with (black lines) presence of tafenoquine $(2.5 \mu \mathrm{g} / \mathrm{ml}, 30$

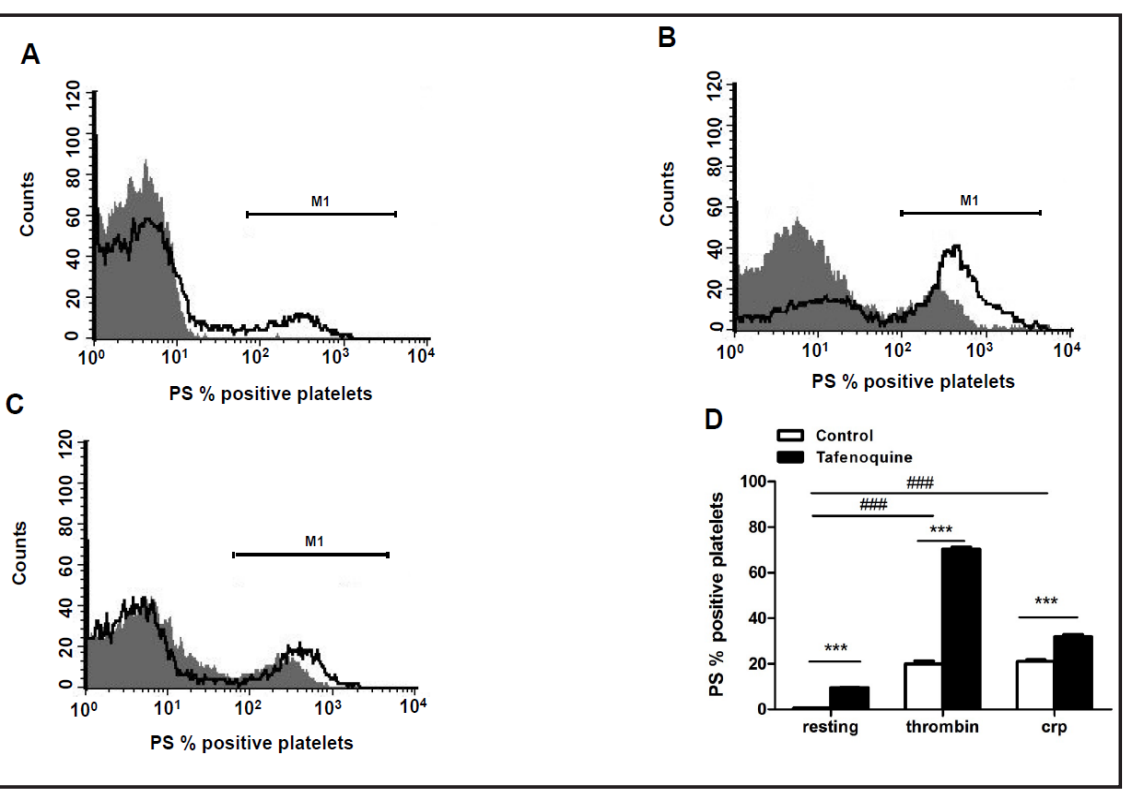

$\mathrm{min})$. D. Arithmetic means \pm SEM $(\mathrm{n}=4)$ of the percentage of annexin-V-binding murine platelets in the absence (white bars) and presence (black bars) of $2.5 \mu \mathrm{g} / \mathrm{ml}$ tafenoquine without (resting) and with a 10 min thrombin $(0.01 \mathrm{U} / \mathrm{ml})$ or CRP $(5 \mu \mathrm{g} / \mathrm{ml})$ treatment. \#\#\# $(p<0.001)$ indicates statistically significant difference from absence of thrombin and CRP, ${ }^{* * *}(\mathrm{p}<0.001)$ indicates statistically significant difference from absence of tafenoquine.

thrombin or CRP was followed by a sharp increase of active integrin $\alpha_{\mathrm{Ib}} \beta_{3}$, an effect significantly blunted in the presence of tafenoquine (Fig. 3).

Phosphatidylserine abundance was estimated from annexin-V-binding. As illustrated in Fig. 4 , the percentage of annexin- $V$ positive platelets was markedly and significantly enhanced by treatment of the platelets with thrombin or CRP. In the absence of thrombin and CRP, treatment with tafenoquine was followed by a slight but significant increase of the percentage of annexin- $V$ 
Fig. 5. Tafenoquine sensitive platelet forward scatter. A-C. Original histogram overlays of forward scatter reflecting cell volume of murine platelets without (A) and with a 10 min treatment with (B) thrombin (0.01 U/ $\mathrm{ml}$ ) or (C) CRP (5 $\mu \mathrm{g} / \mathrm{ml}$ ) without (grey areas) and with (black lines) presence of tafeno-

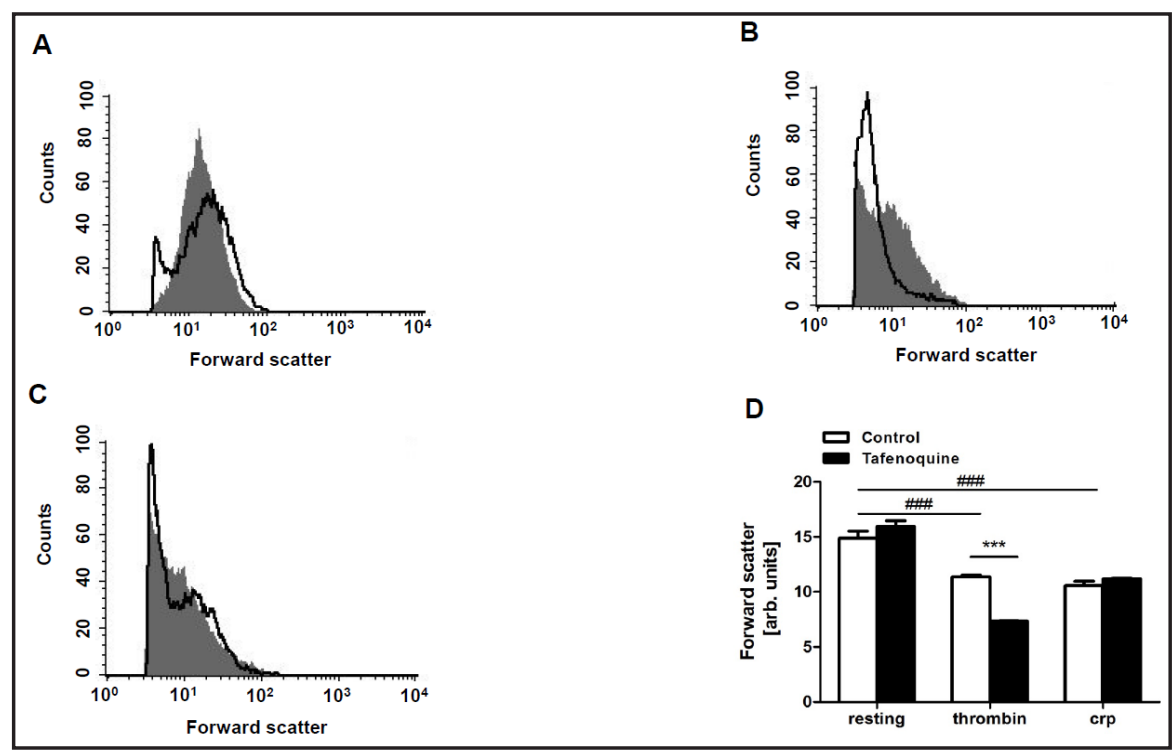
quine $(2.5 \mu \mathrm{g} / \mathrm{ml}, 30 \mathrm{~min})$. D. Arithmetic means \pm SEM $(\mathrm{n}=4)$ of forward scatter reflecting cell volume of murine platelets in the absence (white bars) and presence (black bars) of $2.5 \mu \mathrm{g} / \mathrm{ml}$ tafenoquine without (resting) and with a $10 \mathrm{~min}$ thrombin $(0.01 \mathrm{U} / \mathrm{ml})$ or CRP $(5 \mu \mathrm{g} / \mathrm{ml})$ treatment. \#\#\# $(p<0.001)$ indicates statistically significant difference from absence of thrombin and CRP, ${ }^{* * *}(\mathrm{p}<0.001)$ indicates statistically significant difference from absence of tafenoquine.

binding platelets. Tafenoquine further significantly augmented the effect of thrombin and CRP on the percentage of annexin-V binding platelets (Fig. 4).

Platelet volume was estimated from forward scatter, which was determined by flow cytometry. As illustrated in Fig. 5, both, thrombin and CRP, significantly decreased the forward scatter pointing to cell shrinkage. Tafenoquine treatment did not significantly modify forward scatter in the absence of thrombin or CRP and did not significantly modify the effect of CRP on forward scatter, but significantly augmented the effect of thrombin on the forward scatter (Fig. 5).

The abundance of reactive oxygen species (ROS) was quantified utilizing DCF fluorescence. As illustrated in Fig. 6, the ROS abundance was markedly and significantly enhanced by treatment of the platelets with thrombin or CRP. In the absence of thrombin and CRP, treatment with tafenoquine was followed by a slight but significant increase of the ROS abundance. Tafenoquine further significantly augmented the effect of thrombin and CRP on the ROS abundance (Fig. 6).

A kit has been used for the detection of activated caspase 3. As illustrated in Fig. 7, both, thrombin and CRP, significantly increased the caspase activity. Tafenoquine treatment did not significantly modify caspase activity in the absence of thrombin or CRP and did not significantly modify the effect of CRP on caspase activity, but significantly augmented the effect of thrombin on caspase activity (Fig. 7).

To elucidate the effect of tafenoquine on platelet aggregation, platelets were labeled with two distinct dyes and the coincidence of the two dyes estimated by flow cytometry. As illustrated in Fig. 8, aggregation was markedly and significantly enhanced by treatment of the platelets with thrombin or CRP. In the absence of thrombin and CRP, treatment with tafenoquine was followed by a slight but significant increase of aggregation. Tafenoquine further significantly augmented the effect of thrombin and CRP on aggregation (Fig. 8).

\section{Discussion}

The present observations demonstrate that tafenoquine significantly decreases $\left[\mathrm{Ca}^{2+}\right]_{\mathrm{i}}$ and significantly interferes with the strong up-regulating effect of thrombin and collagen related 
Fig. 6. Tafenoquine sensitive reactive oxygen species (ROS). A-C. Original histogram overlays of DCF fluorescence reflecting ROS abundance (arbitrary units) in murine platelets without (A) and with a 10 min treatment with (B) thrombin $(0.01 \mathrm{U} / \mathrm{ml})$ or $(C)$ CRP $(2 \mu \mathrm{g} / \mathrm{ml})$ without (grey areas) and with (black lines) presence of tafenoquine $(2.5 \mu \mathrm{g} / \mathrm{ml}$,

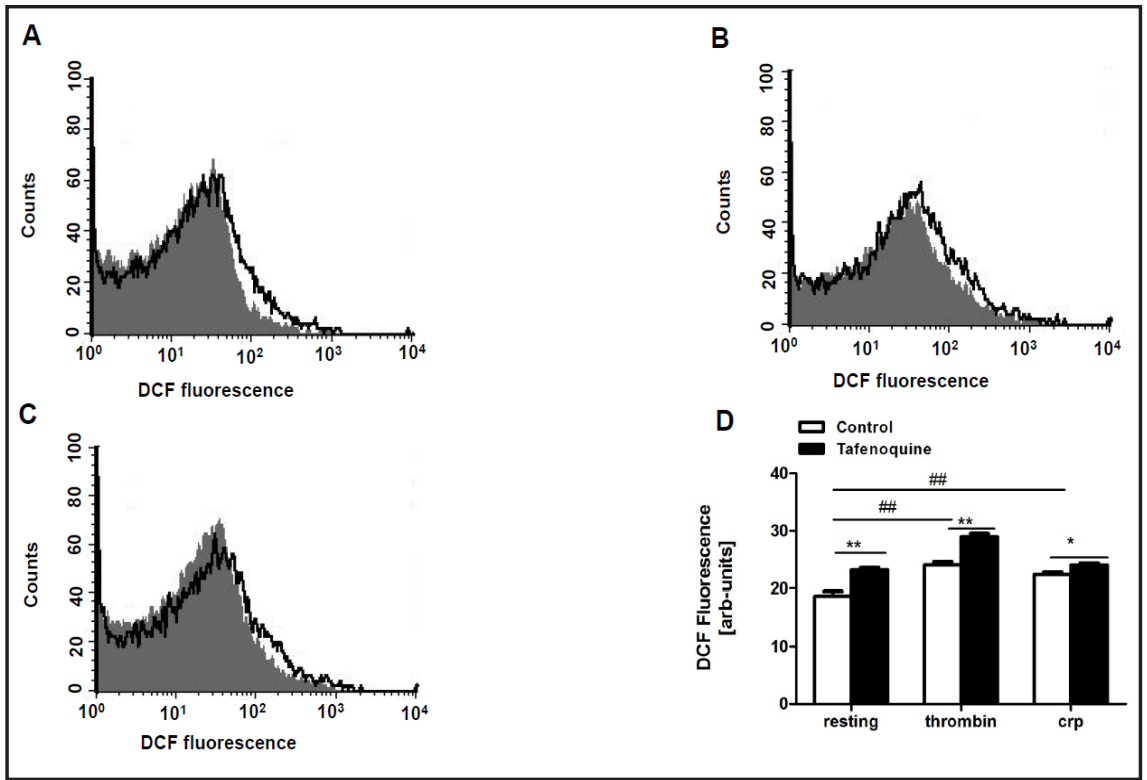
$30 \mathrm{~min})$. D. Arithmetic means \pm SEM $(\mathrm{n}=4)$ of DCF fluorescence reflecting ROS abundance (arbitrary units) in murine platelets in the absence (white bars) and presence (black bars) of $2.5 \mu \mathrm{g} / \mathrm{ml}$ tafenoquine without (resting) and with a $10 \mathrm{~min}$ thrombin $(0.01 \mathrm{U} / \mathrm{ml})$ or CRP $(2 \mu \mathrm{g} / \mathrm{ml})$ treatment. \#\# $(p<0.01)$ indicates statistically significant difference from absence of thrombin and CRP, ${ }^{*}(\mathrm{p}<0.05)^{* *}(\mathrm{p}<0.01)$ indicates statistically significant difference from absence of tafenoquine.

Fig. 7. Tafenoquine sensitive caspase-3 activity. A-C. Original histogram overlays of fluorescence reflecting caspase- 3 activity in murine platelets without (A) and with a 10 min treatment with (B) thrombin (0.01 U/ml) or (C) CRP ( $5 \mu \mathrm{g} / \mathrm{ml}$ ) without (grey areas) and with (black lines) presence of tafenoquine $(2.5 \mu \mathrm{g} / \mathrm{ml}, 30$ min). D. Arithmetic means \pm SEM $(n=4)$ of the percentage of caspase-3-FITC posi-

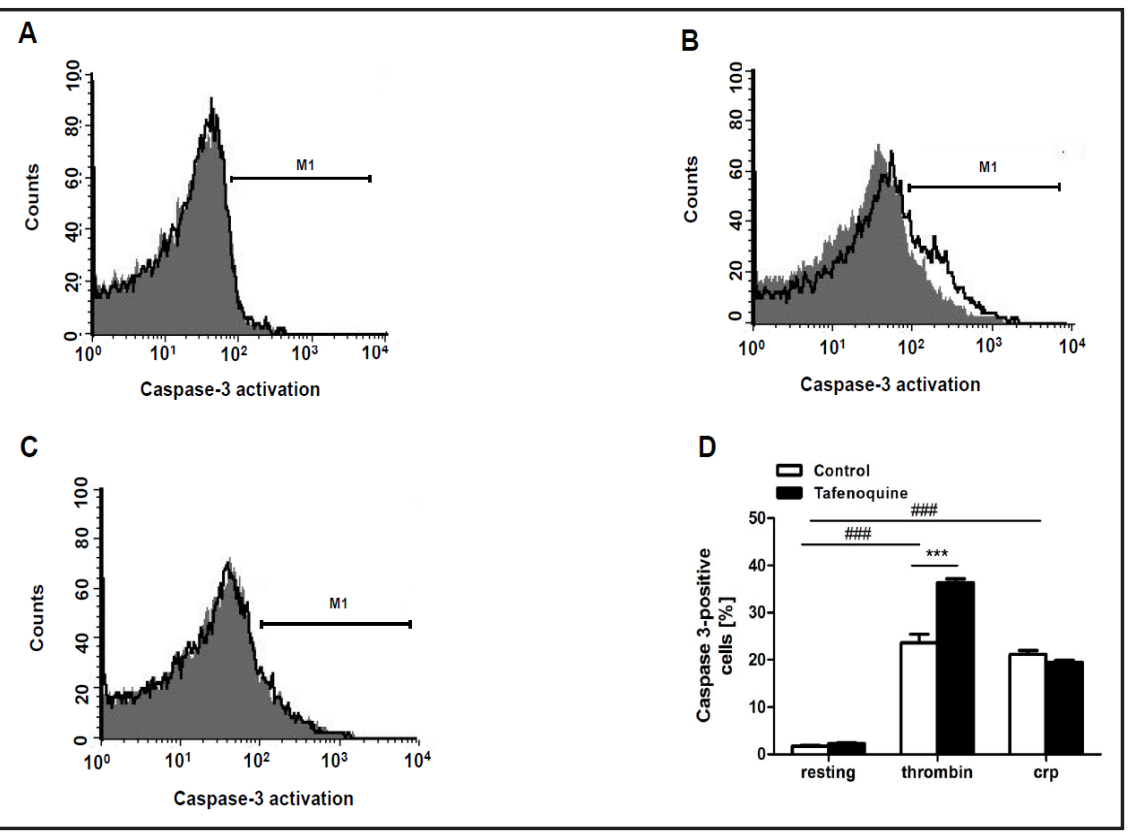
tive murine platelets in the absence (white bars) and presence (black bars) of $2.5 \mu \mathrm{g} / \mathrm{ml}$ tafenoquine without (resting) and with a $10 \mathrm{~min}$ thrombin $(0.01 \mathrm{U} / \mathrm{ml})$ or CRP $(5 \mu \mathrm{g} / \mathrm{ml})$ treatment. \#\#\# ( $p<0.001)$ indicates statistically significant difference from absence of thrombin and CRP, ${ }^{* * *}(\mathrm{p}<0.001)$ indicates statistically significant difference from absence of tafenoquine.

peptide (CRP) on $\left[\mathrm{Ca}^{2+}\right]_{\mathrm{i}^{*}}$ Moreover, tafenoquine slightly increased the P-selectin abundance reflecting platelet degranulation and slightly increased $\alpha_{\mathrm{IIb}} \beta_{3}$ integrin activity in the absence of thrombin and CRP, but significantly blunted the stimulating effect of thrombin and CRP on platelet degranulation and $\alpha_{\mathrm{II}} \beta_{3}$ integrin activity. In contrast, tafenoquine increased cell 


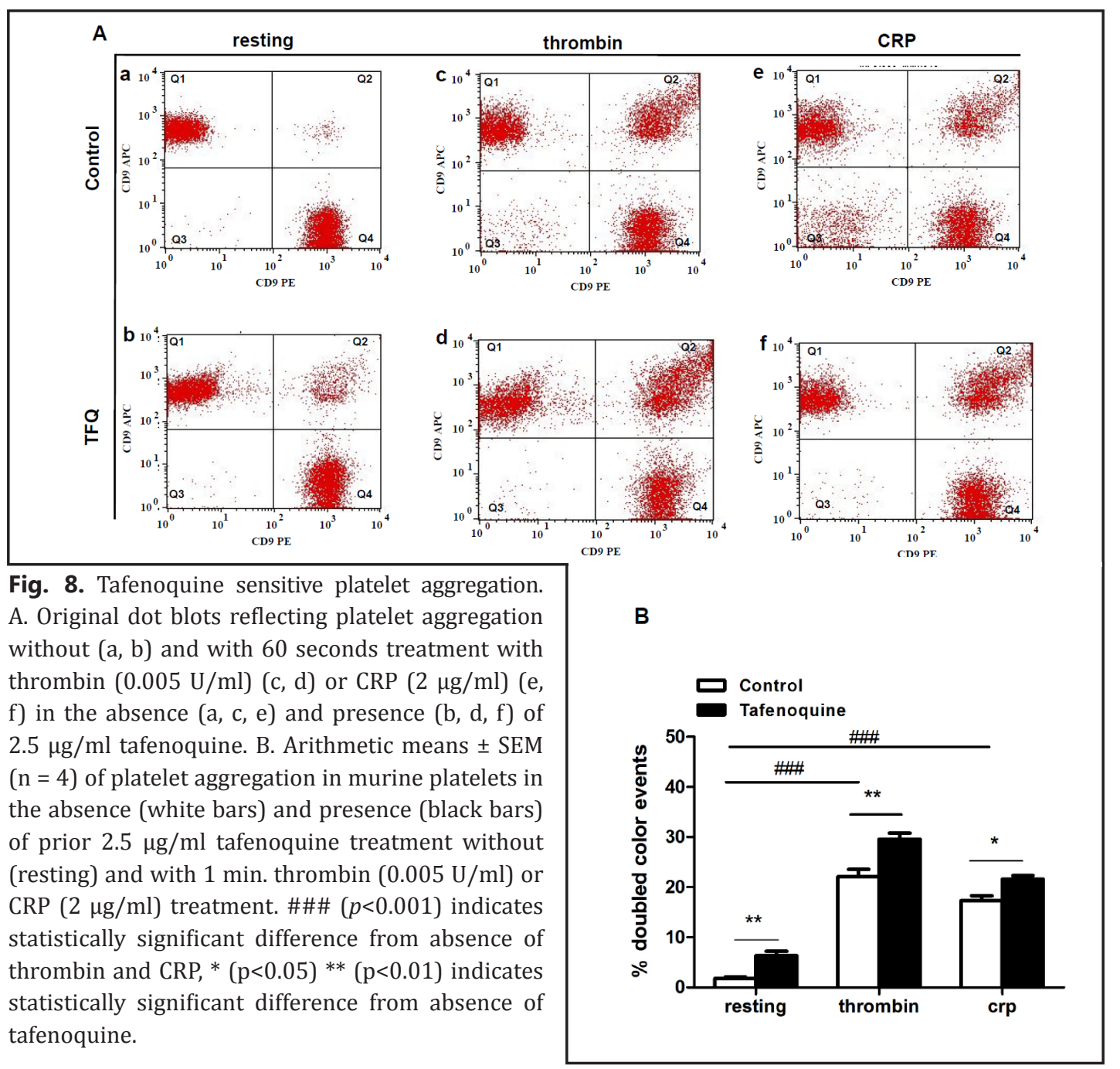

membrane scrambling apparent from annexin-V-binding both, in the absence and presence of thrombin and CRP. Thus, tafenoquine augmented the effect of thrombin and CRP on annexinV-binding. Similarly, tafenoquine augmented the effect of thrombin on forward scatter.

The observed effects of tafenoquine on platelet degranulation and $\alpha_{\mathrm{IIb}} \beta_{3}$ integrin activity may be secondary to its effect on cytosolic $\mathrm{Ca}^{2+}$ activity $\left(\left[\mathrm{Ca}^{2+}\right]_{\mathrm{i}}\right)[39,48]$. An increase of $\left[\mathrm{Ca}^{2+}\right]_{\mathrm{i}}$ is a powerful mechanism triggering platelet activation and may thus lead to development of arterial thrombosis [37]. Increased $\left[\mathrm{Ca}^{2+}\right]_{\mathrm{i}}$ is further a well-known stimulator of cell membrane phospholipid scrambling with translocation of phosphatidylserine to the platelet surface [49-52]. However, tafenoquine stimulates cell membrane scrambling and augments the stimulating effect of thrombin and CRP on cell membrane scrambling, an effect not explained by the observed effects on $\left[\mathrm{Ca}^{2+}\right]_{i}$. Triggering of platelet apoptosis may involve several additional mechanisms including depolarization of the mitochondrial inner membrane with subsequent cytochrome c release and caspase activation [43]. The mitochondria may be influenced by either pro- or anti-apoptotic members of the Bcl-2 family of proteins [43]. The present observations do not allow any safe conclusions as to the mechanisms underlying the effect of tafenoquine on platelet apoptosis. It is noteworthy, however, that stimulation of Trypanosoma and Leishmania death by tafenoquine is preceded by depolarization of the mitochondrial membrane and production of reactive oxygen species $[28,30,32]$. Tafenoquine triggers, however, the suicidal death of erythrocytes, i.e. of cells 


\section{Cellular Physiology Cell Physiol Biochem 2017;41:369-380

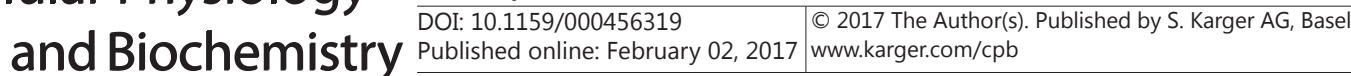 \\ Cao et al.: Tafenoquine Sensitive Platelet Function}

lacking mitochondria [34]. Thus, mitochondria are not required for the effect of tafenoquine on cell death.

Whatever mechanism involved, phosphatidylserine translocation to the platelet surface supports the procoagulant function of platelets and thus contributes to stimulation of hemostasis [53]. Eventually, phosphatidylserine exposing platelets are further bound to and engulfed by macrophages [54].

In conclusion, treatment of platelets with tafenoquine decreases cytosolic $\mathrm{Ca}^{2+}$ activity and blunts the effect of thrombin and CRP on degranulation and $\alpha_{\mathrm{IIb}} \beta_{3}$ integrin activity. By the same token, tafenoquine augments the effect of thrombin and CRP on cell membrane scrambling and aggregation. Whether or not those effects modify platelet activation and aggregation in vivo, remains to be shown.

\section{Acknowledgements}

The authors acknowledge the meticulous preparation of the manuscript by Tanja Loch. The study was supported by the Deutsche Forschungsgemeinschaft Open Access Publishing Fund of Tuebingen University.

\section{Disclosure Statement}

All authors declare that there are no conflicts of interest.

\section{References}

1 Crockett M, Kain KC: Tafenoquine: a promising new antimalarial agent. Expert Opin Investig Drugs 2007;16:705-715.

- Hale BR, Owusu-Agyei S, Fryauff DJ, Koram KA, Adjuik M, Oduro AR, Prescott WR, Baird JK, Nkrumah F, Ritchie TL, Franke ED, Binka FN, Horton J, Hoffman SL: A randomized, double-blind, placebo-controlled, dose-ranging trial of tafenoquine for weekly prophylaxis against Plasmodium falciparum. Clin Infect Dis 2003;36:541-549.

- 3 Lell B, Faucher JF, Missinou MA, Borrmann S, Dangelmaier O, Horton J, Kremsner PG: Malaria chemoprophylaxis with tafenoquine: a randomised study. Lancet 2000;355:2041-2045.

4 Pradines B, Mamfoumbi MM, Tall A, Sokhna C, Koeck JL, Fusai T, Mosnier J, Czarnecki E, Spiegel A, Trape JF, Kombila M, Rogier C: In vitro activity of tafenoquine against the asexual blood stages of Plasmodium falciparum isolates from Gabon, Senegal, and Djibouti. Antimicrob Agents Chemother 2006;50:3225-3226.

5 Ramharter M, Noedl H, Thimasarn K, Wiedermann G, Wernsdorfer G, Wernsdorfer WH: In vitro activity of tafenoquine alone and in combination with artemisinin against Plasmodium falciparum. Am J Trop Med Hyg 2002;67:39-43.

6 Shanks GD, Oloo AJ, Aleman GM, Ohrt C, Klotz FW, Braitman D, Horton J, Brueckner R: A new primaquine analogue, tafenoquine (WR 238605), for prophylaxis against Plasmodium falciparum malaria. Clin Infect Dis 2001;33:1968-1974.

7 Vollnberg A, Prajakwong S, Sirichaisinthop J, Wiedermann G, Wernsdorfer G, Wernsdorfer WH: In-vitro interaction of tafenoquine and chloroquine in Plasmodium falciparum from northwestern Thailand. Wien Klin Wochenschr 2003;115 Suppl 3:28-32.

8 Walsh DS, Eamsila C, Sasiprapha T, Sangkharomya S, Khaewsathien P, Supakalin P, Tang DB, Jarasrumgsichol P, Cherdchu C, Edstein MD, Rieckmann KH, Brewer TG: Efficacy of monthly tafenoquine for prophylaxis of Plasmodium vivax and multidrug-resistant P. falciparum malaria. J Infect Dis 2004;190:1456-1463. 


\section{Cellular Physiology Cell Physiol Biochem 2017;41:369-380

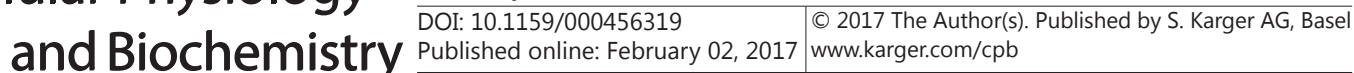 \\ Cao et al.: Tafenoquine Sensitive Platelet Function}

-9 Beck HP, Wampfler R, Carter N, Koh G, Osorio L, Rueangweerayut R, Krudsood S, Lacerda MV, LlanosCuentas A, Duparc S, Rubio JP, Green JA: Estimation of the Antirelapse Efficacy of Tafenoquine, Using Plasmodium vivax Genotyping. J Infect Dis 2016;213:794-799.

10 Dow GS, Liu J, Lin G, Hetzell B, Thieling S, McCarthy WF, Tang D, Smith B: Summary of anti-malarial prophylactic efficacy of tafenoquine from three placebo-controlled studies of residents of malaria-endemic countries. Malar J 2015;14:473.

-11 Dow GS, McCarthy WF, Reid M, Smith B, Tang D, Shanks GD: A retrospective analysis of the protective efficacy of tafenoquine and mefloquine as prophylactic anti-malarials in non-immune individuals during deployment to a malaria-endemic area. Malar J 2014;13:49.

12 Elmes NJ, Nasveld PE, Kitchener SJ, Kocisko DA, Edstein MD: The efficacy and tolerability of three different regimens of tafenoquine versus primaquine for post-exposure prophylaxis of Plasmodium vivax malaria in the Southwest Pacific. Trans R Soc Trop Med Hyg 2008;102:1095-1101.

13 Kitchener S, Nasveld P, Edstein MD: Tafenoquine for the treatment of recurrent Plasmodium vivax malaria. Am J Trop Med Hyg 2007;76:494-496.

14 Leary KJ, Riel MA, Roy MJ, Cantilena LR, Bi D, Brater DC, van de Pol C, Pruett K, Kerr C, Veazey JM, Jr., Beboso R, Ohrt C: A randomized, double-blind, safety and tolerability study to assess the ophthalmic and renal effects of tafenoquine $200 \mathrm{mg}$ weekly versus placebo for 6 months in healthy volunteers. Am J Trop Med Hyg 2009;81:356-362.

15 Li Q O'Neil M, Xie L, Caridha D, Zeng Q Zhang J, Pybus B, Hickman M, Melendez V: Assessment of the prophylactic activity and pharmacokinetic profile of oral tafenoquine compared to primaquine for inhibition of liver stage malaria infections. Malar J 2014;13:141.

-16 Llanos-Cuentas A, Lacerda MV, Rueangweerayut R, Krudsood S, Gupta SK, Kochar SK, Arthur P, Chuenchom N, Mohrle JJ, Duparc S, Ugwuegbulam C, Kleim JP, Carter N, Green JA, Kellam L: Tafenoquine plus chloroquine for the treatment and relapse prevention of Plasmodium vivax malaria (DETECTIVE): a multicentre, double-blind, randomised, phase 2b dose-selection study. Lancet 2014;383:1049-1058.

17 Marcsisin SR, Sousa JC, Reichard GA, Caridha D, Zeng Q Roncal N, McNulty R, Careagabarja J, Sciotti RJ, Bennett JW, Zottig VE, Deye G, Li Q, Read L, Hickman M, Dhammika Nanayakkara NP, Walker LA, Smith B, Melendez V, Pybus BS: Tafenoquine and NPC-1161B require CYP 2D metabolism for anti-malarial activity: implications for the 8-aminoquinoline class of anti-malarial compounds. Malar J 2014;13:2.

18 Miller AK, Harrell E, Ye L, Baptiste-Brown S, Kleim JP, Ohrt C, Duparc S, Mohrle JJ, Webster A, Stinnett S, Hughes A, Griffith S, Beelen AP: Pharmacokinetic interactions and safety evaluations of coadministered tafenoquine and chloroquine in healthy subjects. Br J Clin Pharmacol 2013;76:858-867.

19 Nasveld P, Kitchener S: Treatment of acute vivax malaria with tafenoquine. Trans R Soc Trop Med Hyg 2005;99:2-5.

20 Nasveld P, Kitchener S, Edstein M, Rieckmann K: Comparison of tafenoquine (WR238605) and primaquine in the post-exposure (terminal) prophylaxis of vivax malaria in Australian Defence Force personnel. Trans R Soc Trop Med Hyg 2002;96:683-684.

21 Ponsa N, Sattabongkot J, Kittayapong P, Eikarat N, Coleman RE: Transmission-blocking activity of tafenoquine (WR-238605) and artelinic acid against naturally circulating strains of Plasmodium vivax in Thailand. Am J Trop Med Hyg 2003;69:542-547.

22 Rajapakse S, Rodrigo C, Fernando SD: Tafenoquine for preventing relapse in people with Plasmodium vivax malaria. Cochrane Database Syst Rev 2015;10.1002/14651858.CD010458.pub2CD010458.

-23 St Jean PL, Xue Z, Carter N, Koh GC, Duparc S, Taylor M, Beaumont C, Llanos-Cuentas A, Rueangweerayut R, Krudsood S, Green JA, Rubio JP: Tafenoquine treatment of Plasmodium vivax malaria: suggestive evidence that CYP2D6 reduced metabolism is not associated with relapse in the Phase 2b DETECTIVE trial. Malar J 2016;15:97.

24 Tenero D, Green JA, Goyal N: Exposure-Response Analyses for Tafenoquine after Administration to Patients with Plasmodium vivax Malaria. Antimicrob Agents Chemother 2015;59:6188-6194.

25 Vuong C, Xie LH, Potter BM, Zhang J, Zhang P, Duan D, Nolan CK, Sciotti RJ, Zottig VE, Nanayakkara NP, Tekwani BL, Walker LA, Smith PL, Paris RM, Read LT, Li Q, Pybus BS, Sousa JC, Reichard GA, Smith B, Marcsisin SR: Differential cytochrome P450 2D metabolism alters tafenoquine pharmacokinetics. Antimicrob Agents Chemother 2015;59:3864-3869. 


\section{Cellular Physiology Cell Physiol Biochem 2017;41:369-380

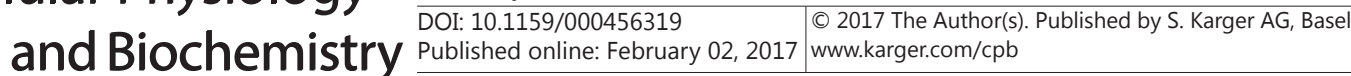

26 Walsh DS, Looareesuwan S, Wilairatana P, Heppner DG, Jr., Tang DB, Brewer TG, Chokejindachai W, Viriyavejakul P, Kyle DE, Milhous WK, Schuster BG, Horton J, Braitman DJ, Brueckner RP: Randomized dose-ranging study of the safety and efficacy of WR 238605 (Tafenoquine) in the prevention of relapse of Plasmodium vivax malaria in Thailand. J Infect Dis 1999;180:1282-1287.

27 Walsh DS, Wilairatana P, Tang DB, Heppner DG, Jr., Brewer TG, Krudsood S, Silachamroon U, Phumratanaprapin W, Siriyanonda D, Looareesuwan S: Randomized trial of 3-dose regimens of tafenoquine (WR238605) versus low-dose primaquine for preventing Plasmodium vivax malaria relapse. Clin Infect Dis 2004;39:1095-1103.

28 Carvalho L, Martinez-Garcia M, Perez-Victoria I, Manzano JI, Yardley V, Gamarro F, Perez-Victoria JM: The Oral Antimalarial Drug Tafenoquine Shows Activity against Trypanosoma brucei. Antimicrob Agents Chemother 2015;59:6151-6160.

29 Yardley V, Gamarro F, Croft SL: Antileishmanial and antitrypanosomal activities of the 8-aminoquinoline tafenoquine. Antimicrob Agents Chemother 2010;54:5356-5358.

-30 Carvalho L, Luque-Ortega JR, Manzano JI, Castanys S, Rivas L, Gamarro F: Tafenoquine, an antiplasmodial 8-aminoquinoline, targets leishmania respiratory complex III and induces apoptosis. Antimicrob Agents Chemother 2010;54:5344-5351.

31 Manzano JI, Carvalho L, Garcia-Hernandez R, Poveda JA, Ferragut JA, Castanys S, Gamarro F: Uptake of the antileishmania drug tafenoquine follows a sterol-dependent diffusion process in Leishmania. J Antimicrob Chemother 2011;66:2562-2565.

-32 Manzano JI, Carvalho L, Perez-Victoria JM, Castanys S, Gamarro F: Increased glycolytic ATP synthesis is associated with tafenoquine resistance in Leishmania major. Antimicrob Agents Chemother 2011;55:10451052.

-33 Nasveld PE, Edstein MD, Reid M, Brennan L, Harris IE, Kitchener SJ, Leggat PA, Pickford P, Kerr C, Ohrt C, Prescott W, Tafenoquine Study T: Randomized, double-blind study of the safety, tolerability, and efficacy of tafenoquine versus mefloquine for malaria prophylaxis in nonimmune subjects. Antimicrob Agents Chemother 2010;54:792-798.

34 Bhuyan AAC, Bissinger R, Stockinger K, Lang F: Stimulation of Suicidal Erythrocyte Death by Tafenoquine. Cell Physiol Biochem 2016;39:2464-2476.

35 Gawaz M: Role of platelets in coronary thrombosis and reperfusion of ischemic myocardium. Cardiovasc Res 2004;61:498-511.

-36 Varga-Szabo D, Braun A, Nieswandt B: Calcium signaling in platelets. J Thromb Haemost 2009;7:10571066.

37 Bergmeier W, Stefanini L: Novel molecules in calcium signaling in platelets. J Thromb Haemost 2009;7 Suppl 1:187-190.

-38 Braun A, Varga-Szabo D, Kleinschnitz C, Pleines I, Bender M, Austinat M, Bosl M, Stoll G, Nieswandt B: Orai1 (CRACM1) is the platelet SOC channel and essential for pathological thrombus formation. Blood 2009;113:2056-2063.

39 Varga-Szabo D, Braun A, Nieswandt B: STIM and Orai in platelet function. Cell Calcium 2011;50:270-278.

-40 Wang Y, Deng X, Gill DL: Calcium signaling by STIM and Orai: intimate coupling details revealed. Sci Signal 2010;3:pe42.

41 Liu G, Cao H, Liu G, Heinzmann D, Chen H, Umbach AT, Gawaz M, Lang F: Effect of Lysosomotropic Polyamineoxidase Inhibitor MDL-72527 on Platelet Activation. Cell Physiol Biochem 2016;38:1695-1702.

-42 Liu G, Liu G, Chatterjee M, Umbach AT, Chen H, Gawaz M, Lang F: Influence of gamma-Secretase Inhibitor 24-Diamino-5-Phenylthiazole DAPT on Platelet Activation. Cell Physiol Biochem 2016;38:726-736.

43 Gyulkhandanyan AV, Mutlu A, Freedman J, Leytin V: Markers of platelet apoptosis: methodology and applications. J Thromb Thrombolysis 2012;33:397-411.

44 Liu G, Liu G, Chen H, Borst O, Gawaz M, Vortkamp A, Schreiber R, Kunzelmann K, Lang F: Involvement of Ca2+ Activated Cl- Channel Ano6 in Platelet Activation and Apoptosis. Cell Physiol Biochem 2015;37:19341944.

45 Pelzl L, Fakhri H, Umbach AT, Gawaz M, Paulmichl M, Lang F: Sgk1 sensitive pendrin expression in murine platelets. Cell Physiol Biochem 2013;32:210-220.

46 Liu G, Liu G, Chen H, Alzoubi K, Umbach AT, Gawaz M, Stournaras C, Lang F: Rapid Upregulation of Orai1 Abundance in the Plasma Membrane of Platelets Following Activation with Thrombin and Collagen Related Peptide. Cell Physiol Biochem 2015;37:1759-1766. 


\section{Cellular Physiology Cell Physiol Biochem 2017;41:369-380

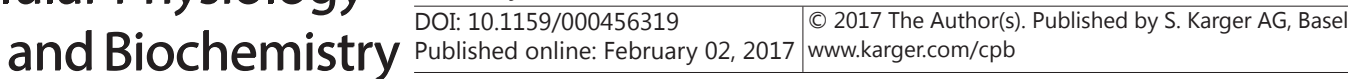 \\ Cao et al.: Tafenoquine Sensitive Platelet Function}

47 Dong J, Lin J, Wang B, He S, Wu C, Kushwaha KK, Mohabeer N, Su Y, Fang H, Huang K, Li D: Inflammatory cytokine TSLP stimulates platelet secretion and potentiates platelet aggregation via a TSLPR-dependent PI3K/Akt signaling pathway. Cell Physiol Biochem 2015;35:160-174.

48 Lang F, Munzer P, Gawaz M, Borst O: Regulation of STIM1/Orai1-dependent Ca2+ signalling in platelets. Thromb Haemost 2013;110:925-930.

49 Borst O, Munzer P, Gatidis S, Schmidt EM, Schonberger T, Schmid E, Towhid ST, Stellos K, Seizer P, May $\mathrm{AE}$, Lang F, Gawaz M: The inflammatory chemokine CXC motif ligand 16 triggers platelet activation and adhesion via CXC motif receptor 6-dependent phosphatidylinositide 3-kinase/Akt signaling. Circ Res 2012;111:1297-1307.

50 Harper MT, Poole AW: Store-operated calcium entry and non-capacitative calcium entry have distinct roles in thrombin-induced calcium signalling in human platelets. Cell Calcium 2011;50:351-358.

51 Mahaut-Smith MP: A role for platelet TRPC channels in the $\mathrm{Ca} 2+$ response that induces procoagulant activity. Sci Signal 2013;6:pe23.

52 Mushtaq M, Nam TS, Kim UH: Critical role for CD38-mediated Ca2+ signaling in thrombin-induced procoagulant activity of mouse platelets and hemostasis. J Biol Chem 2011;286:12952-12958.

53 Lhermusier T, Chap H, Payrastre B: Platelet membrane phospholipid asymmetry: from the characterization of a scramblase activity to the identification of an essential protein mutated in Scott syndrome. J Thromb Haemost 2011;9:1883-1891.

54 Badlou BA, Wu YP, Smid WM, Akkerman JW: Platelet binding and phagocytosis by macrophages. Transfusion 2006;46:1432-1443. 